\title{
Covid-19: GPs can stop health checks for over 75s and routine medicine reviews
}

\author{
Abi Rimmer
}

The BMJ

GPs can stop or postpone some routine work to free them up to deal with covid-19, NHS England and NHS Improvement has said.

In a letter sent to GPs and commissioners Nikita Kanani, medical director for primary care, and Ed Waller, director of primary care strategy, set out a list of activities that GPs could stop doing or postpone. ${ }^{1}$ It included health checks for people over 75 , which it said GPs could stop doing "if in their judgment that is not the right priority."

The letter also said that routine medical reviews could be deferred until October if necessary, "unless they can be viably conducted remotely and/or in exceptional cases in person or by home visit as per local clinical discretion." Key medicine reviews where a patient is being regularly monitored should continue, it advised.

The letter added that practices' Quality Outcomes Framework (QOF) income in 2020-21 would be protected "as necessary to respond to covid-19" and that one-off adjustments would be made for practices that earned less from QOF payments in 2019-20 than in 2018-19 as a result of covid-19 activities.

However, practices would be asked to consider stopping any private work they were doing to help free up capacity, the letter said.

\section{Reassurance on flexibilities}

Responding to the letter, Ruth Rankine, primary care network development director at the NHS Confederation, and Julie
Wood, chief executive of NHS Clinical Commissioners, said, "We welcome greater clarity for primary care networks (PCNs) and general practice. This guidance goes some way to providing reassurance on the flexibilities that are available, although much of this is already happening.

"Clinical commissioning groups (CCGs) must now ensure they are supporting their PCNs and practices. The need is now even greater for direct connection and support between CCGs and primary care, in both communication and planning."

Other organisations have also made changes to lessen the burden on doctors. On 16 March the Care Quality Commission announced that it would stop routine inspections. ${ }^{2}$ And on 18 March the General Medical Council announced that revalidation dates from 17 March to the end of September would be deferred for a year. ${ }^{3}$

Kanani N, Waller E. Letter to GPs and their commissioners: Next steps on general practice response to covid-19. 19 Mar 2020 https://mcusercontent.com/ feeed3bba7c179fd3a7ef554/files/799d0ae8-fb69-4860-8c6c-5678698a0a7a/ Preparedness_letter_primary_care_19_March_2020.pdf.

2 Care Quality Commission. CQC to stop routine inspections to focus on supporting providers to deliver safe care during COVID-19 pandemic. 16 Mar 2020. https://www.cqc.org.uk/ news/releases/cqc-stop-routine-inspections-focus-supporting-providers-deliver-safe-careduring-cov- 0 .

3 General Medical Council. Twitter. 19 Mar 2020. https://twitter.com/gmcuk/status/ 1240576809659482112.

Published by the BMJ Publishing Group Limited. For permission to use (where not already granted under a licence) please go to http://group.bmj.com/group/rights-licensing/ permissions 